

\section{MEAT EFFICIENCY}

To reach the recommended daily intake of 18 milligrams of iron, a woman would have to eat at least 8 times more spinach than cooked liver. Iron found in vegetables is also harder for the body to absorb, because it is usually bound to fibre.

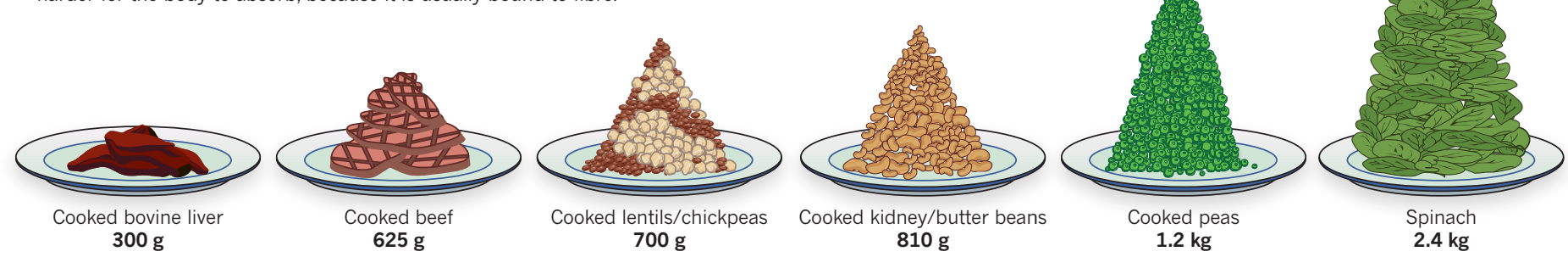

These data are approximate and will vary depending on factors such as preparation technique, soil or feeding conditions, and time between harvesting and intake. Analysis by F. Mori Sarti based on data from http://ndb.nal.usda.gov and http://www.unicamp.br/

researcher at the Australian National University in Canberra.

To fill this gap, Hosking and her team asked 352 Australians aged between 65 and 90 years old - who were cognitively healthy and predominantly from a middle- or high-income background - to recall what sorts of food they ate growing up ${ }^{5,6}$. For instance, how often did they eat items such as carrots, meat, fish or cake? The researchers then administered cognitive tests.

Hosking found no correlation between the volunteers' test performance and their consumption of meat as children. The results contradicted what Neumann and others have observed in developing countries. What's more, contrary to conventional wisdom, participants who consumed more fish during childhood and as adults were actually slower on measures of cognitive speed. (The fish might have contained neurocontaminants such as mercury, she says.)

There are several issues that affect these results, says Hosking. One is that people don't eat single foods, but patterns of foods, making it difficult to tease out the importance of an individual food type, such as meat. In the older Australians for instance, those who ate meat were also more likely to consume packaged desserts and snack foods.

Moreover, what the animal eats also matters. Livestock and poultry in Western nations are often raised in large facilities and fed diets that consist mainly of maize and soya, whereas animals from poor villages are typically farmed on a much smaller scale and forage for a greater variety of foods, which increases the nutrient content of their meat. Given these sorts of variations, Hosking says, "we have to be very cautious about making dietary recommendations ... for people who have access to large quantities of food."

\section{MEAT IN THE BRAIN}

The micronutrients in meat have become an essential part of our diet over millennia. A few years ago, archaeologists in Tanzania unearthed fragments of a child's skull dating back 1.5 million years. Deformities on the bones suggested that the child had died from porotic hyperostosis, a condition thought to result from a deficiency in vitamin B12 - found exclusively in animal-derived foods. Humans started eating dairy products only in the past 5,000 years, meaning that the child had almost certainly died from a lack of meat ${ }^{7}$. So, by at least 1.5 million years ago, says Domínguez-Rodrigo, humans had become so adapted to eating meat that without it they would die.

Research is starting to provide some clues as to how meat helps the brain to function. Bradley Peterson, director of the Institute for the Developing Mind at "Meat can Children's Hospital Los beaworm, Angeles in California, caterpillar has investigated why low or termite. It iron levels in children are doesn'thave correlated with lower IQ to be butcher and poor concentration ${ }^{8}$. meat." Using magnetic resonance imaging, Peterson and his colleagues mapped out what happened in the brains of newborn infants of 40 adolescent mothers - a group known to be at high risk for iron deficiency. Although most of the women reported taking prenatal vitamins with iron, $58 \%$ had iron levels below normal and $14 \%$ met the criteria for mild anaemia.

As the brain develops, says Peterson, neurons become increasingly complex, forming branchlike dendrites covered with spines - much like a growing tree. The brain images that his team took showed a correlation between neuron complexity in an infant and the amount of iron in the mother's diet. "The higher the iron intake throughout pregnancy, the more mature or the more complex grey matter was at the time of birth," says Peterson, who is continuing to track the mothers and babies to see how those variations play out.

Beyond simple measures of micronutrient intake, individual requirements are also influenced by a person's genetics. So far, much of the research has focused on how people process omega-3 fatty acids, chiefly DHA and eicosapentaenoic acid (EPA), which are crucial for human cognitive health.

Omega-3 fatty acids are found primarily in oily, wild fish, such as salmon and tuna, but pasture-raised animals are also a good source. (Animals fed only soya or maize have fewer omega-3s.) In 2012, researchers discovered that most African populations, but not European populations, carried a variant of the FADS gene that made them more efficient at converting omega-3s in plants into a usable form, meaning that they required less from animal sources ${ }^{9}$. Conversely, a 2014 paper reported that people carrying a variant of the $A P O E$ gene (11-17\% of US individuals of European descent) that confers a greater risk of developing late-onset Alzheimer's disease, derived little benefit from eating fatty fish ${ }^{10}$. "One size does not fit all around nutritional recommendations," says Hosking. Put another way, the nutrients found in meat are important for health and cognition, but only up to a point. "Meat packs a lot of minerals and vitamins in just a small amount of food," says Domínguez-Rodrigo. "Eating meat is like eating a power bar."

So the key question becomes how much meat should a cognitive-health-conscious person eat. Too little can delay development and cognition. But too much, particularly if it is low quality and mass produced, is associated with other health concerns, such as heart disease and cancer, along with memory problems later in life. A person's life stage matters: pregnant women need more iron, as do babies and children. Genetics also play a part, but we don't yet know all the particulars. All these caveats make for a murky takeaway.

Sujata Gupta is a freelance science writer based in Burlington, Vermont.

1. Domínguez-Rodrigo, M., Rayne Pickering, T., Semaw, S. \& Rogers, M. J. J. Hum. Evol. 48, 109-121 (2005).

2. Neumann, C., Bwibo, N. O. \& Sigman, M. Final Report Phase II: Functional Implications of Malnutrition, Kenya Project. Nutrition CRSP. (University of California, Los Angeles, 1992).

3. Neumann, C. G., Murphy, S. P., Gewa, C., Grillenberger, M. \& Bwibo, N. O. J. Nutr. 137, 1119-1123 (2007).

4. Hulett, J. L. et al. Br. J. Nutr. 111, 875-886 (2014)

5. Hosking, D. E., Nettelbeck, T., Wilson, C. \& Danthiir, V. Br. J. Nutr. 112, 228-237 (2014)

6. Hosking, D. \& Danthiir, V. Br. J. Nutr. 110, 2069 2083 (2013).

7. Domínguez-Rodrigo, M. et al. PLoS ONE 7, e46414 (2012).

8. Monk, C. et al. Pediatric Res, http://dx.doi. org/10.1038/pr.2015.248 (2015)

9. Mathias, R. A. et al. PLoS ONE 7, e44926 (2012).

10.Chouinard-Watkins, R. \& Plourde, M. Nutrients 6 , 4452-4471 (2014). 